\title{
Conserving maize in gene banks: Changes in genetic diversity revealed by morphological and SSR markers
}

\author{
Violeta Andjelkovic ${ }^{{ }^{*}}$, Ana Nikolic ${ }^{1}$, Dragan Kovacevic ${ }^{1}$, Snezana Mladenovic-Drinic ${ }^{1}$, \\ Natalija Kravic ${ }^{1}$, Vojka Babic ${ }^{1}$, Mirjana Srebric ${ }^{1}$, Mirjana Jankulovska $^{2}$, Sonja Ivanovska², \\ and Dane Bosev
}

${ }^{1}$ Maize Research Institute Zemun Polje, Slobodana Bajica 1, 11185 Belgrade, Serbia.

*Corresponding author (avioleta@mrizp.rs).

${ }^{2}$ University Ss Cyruk and Methodius, Faculty of Agricultural Sciences and Food, blvd. Aleksandar Makedonski bb, 1000 Skopje, Republic of Macedonia.

Received: 16 August 2017; Accepted: 20 December 2017; doi:10.4067/S0718-58392018000100030

\begin{abstract}
In the second half of $20^{\text {th }}$ century the awareness of importance of landraces for the future, led to organized collecting missions for numerous plant species. A total of 2217 maize (Zea mays L.) landraces, collected in the former Yugoslavia, are stored at Maize Research Institute (MRIZP) gene bank. During 2014, new collecting missions were organized in the eastern and western parts of Macedonia. According to collecting site and kernel type, 14 samples from the Faculty of Agricultural Sciences and Food, R. Macedonia were chosen for the comparison and identification of possible duplicates, through coupling with the 16 MRIZP gene bank accessions from the same area and kernel characteristics. Phenotypic characterization was done for 21 traits according to International Board for Plant Genetic Resources descriptors for maize. The Principal Component Analysis (PCA) identifies five PCs with Eigenvalue $>1$, explaining $80 \%$ of the total phenotypic variation. The most discriminative traits with the strongest positive associations were tasseling and silking dates, plant height, leaf length and ear length. Compared to the $e x$ situ populations, the number of alleles and the number of specific alleles, showed a significant decrease in the in situ populations. Twelve unique alleles were detected in samples from MRIZP gene bank, and only four were found in new Macedonian samples. Cluster analysis of morphological and molecular markers distinguished groups of maize accessions with distinctive morphological traits and genetic profiles that will be useful for conservation, and management of gene bank collection, as well as for possible utilization in breeding.
\end{abstract}

Key words: Accessions, landraces, molecular markers, variability, Zea mays.

\section{INTRODUCTION}

Maize genetic resources are of high importance for agriculture, but breeding of modern hybrids in the second half of the $20^{\text {th }}$ century, contributed to rapid replacement of traditional landraces in Europe. The need for preventing the loss of maize (Zea mays L.) genetic diversity led to organized collecting missions. Since landraces are a valuable source of potentially useful traits, there is necessity to properly conserve and characterize them, prevent from disappearing, and to keep for utilization in breeding.

Ex situ method is very useful for seed conservation in gene banks. In contrast, in situ conservation protects diversity and identifies varieties with useful and adaptive genes. Many maize gene banks were established in 
different countries, and characterization of genetic diversity was carried out (Rebourg et al., 2001). Global Plan of Action for Conservation and Sustainable Utilization of Plant Genetic Resources for Food and Agriculture (FAO, 1996) recommended increase efficiency in ex situ conservation by the development of core collections and reduction in duplicate accessions within and between collections.

However, the usefulness of applied morphological characterization of gene bank accessions became limited, since they are strongly affected by environment. In the last few decades, application of molecular markers for polymorphism evaluation at the DNA level has been very successful in genetic diversity studies (Ignjatovic-Micic et al., 2008; Drinic Mladenovic et al., 2012; Barcaccia et al., 2016). Since molecular characterization of accessions is becoming more important for identification and elimination of potential duplicates in collections (Reif et al., 2004), relationship between diversity on morphological and molecular level, could be of high importance for conservation in gene bank.

Replacement of local maize landraces with hybrid maize in the second half of the $20^{\text {th }}$ century occurred in former Yugoslavia territory (western Balkan region, Andjelkovic and Ignjatovic-Micic, 2012). Collection, characterization, and natural classification in coming decades resulted in more than 2000 local maize landraces stored at Maize Research Institute Zemun Polje (MRIZP) gene bank, and out of them, 222 landraces collected in the Republic of Macedonia (Andjelkovic and Ignjatovic-Micic, 2012).

In the present paper, 14 pairs of maize landraces, collected in Republic of Macedonia in the second part of $20^{\text {th }}$ century, and in 2014, were compared by morphological traits (International Board for Plant Genetic Resources; IBPGR, 2008) and microsatellite markers, with the aim to examine variation in genetic diversity of landraces in past $40 \mathrm{yrs}$. The results of the assessment will contribute to the more efficient ex situ conservation, management, and rationalization of gene bank collection, e.g. elimination of potential duplicate accessions.

\section{MATERIALS AND METHODS}

\section{Field trails}

To analyze temporal changes in genetic diversity, 73 samples from the Faculty of Agricultural Sciences and Food, Republic of Macedonia (FASFMK) collection, and 222 accessions from MRIZP gene bank were paired, based on the collection sites, and kernel color and texture, since kernel color, type and texture are initial steps for monitoring accession identity, according to guidelines (http://cropgenebank.sgrp.cgiar.org/images/file/maize/Maize_ENG.pdf). After comparison, 16 accessions represented ex-situ accessions, collected in different years $(1974,1975,1978$, 1980, 1983, 1984, and 1989) and conserved at MRIZP gene bank, and 14 in-situ samples collected from farmers in 2014 from several locations in the Republic of Macedonia (Table 1, Figure 1), were chosen for evaluation.

For $e x$-situ samples, seeds were taken from regeneration stocks from MRIZP gene bank, after up to five times of multiplication (detailed characterization of landraces is available at https://www.mrizp.rs/emdb/default-en.htm), and from FASFMK collection, for in-situ samples, seeds of landraces collected in 2014, were used. The landraces were

Table 1. List of maize landraces accessions, gene bank identification document (GB ID), collecting site, acquisition year of maize landraces collected in the Republic of Macedonia.

\begin{tabular}{|c|c|c|c|c|c|c|c|c|c|}
\hline $\mathrm{Nr}$ & GB ID & GB & $\begin{array}{c}\text { Collecting } \\
\text { site }\end{array}$ & $\begin{array}{c}\text { Acquisition } \\
\text { year }\end{array}$ & $\mathrm{Nr}$ & Bank ID & GB & $\begin{array}{c}\text { Collecting } \\
\text { site }\end{array}$ & $\begin{array}{c}\text { Acquisition } \\
\text { year }\end{array}$ \\
\hline 1 & MK1 & MK & Stip & 2014 & 15 & MK18 & MK & Gostivar & 2014 \\
\hline 2 & ZP 1818 & SRB & Stip & 1982 & 16 & ZP 1086 & SRB & Gostivar & 1973 \\
\hline 3 & MK37 & MK & Probistip & 2014 & 17 & MK60 & MK & Delcevo & 2014 \\
\hline 4 & ZP 1819 & SRB & Probistip & 1982 & 18 & ZP 2223 & SRB & Delcevo & 1989 \\
\hline 5 & ZP 1820 & SRB & Probistip & 1982 & 19 & MK30 & MK & Skopje & 2014 \\
\hline 6 & MK36 & MK & Probistip & 2014 & 20 & ZP 1642 & SRB & Skopje & 1978 \\
\hline 7 & ZP1822 & SRB & Probistip & 1982 & 21 & ZP 1643 & SRB & Skopje & 1978 \\
\hline 8 & MK52 & MK & Stip & 2014 & 22 & ZP 1645 & SRB & Skopje & 1978 \\
\hline 9 & MK6 & MK & Kavadarci & 2014 & 23 & MK31 & MK & Debar & 2014 \\
\hline 10 & ZP 1682 & SRB & Kavadarci & 1978 & 24 & ZP 1090 & SRB & Debar & 1973 \\
\hline 11 & MK10 & MK & Kocani & 2014 & 25 & ZP 1091 & SRB & Debar & 1973 \\
\hline 12 & ZP 1969 & SRB & Kocani & 1984 & 26 & ZP 1093 & SRB & Debar & 1973 \\
\hline 13 & MK58 & MK & Stip & 2014 & 27 & MK50 & MK & Stip & 2014 \\
\hline 14 & ZP 1172 & SRB & Stip & 1974 & 28 & ZP 1141 & SRB & Stip & 1973 \\
\hline
\end{tabular}


Figure 1. Collecting sites for the maize samples.

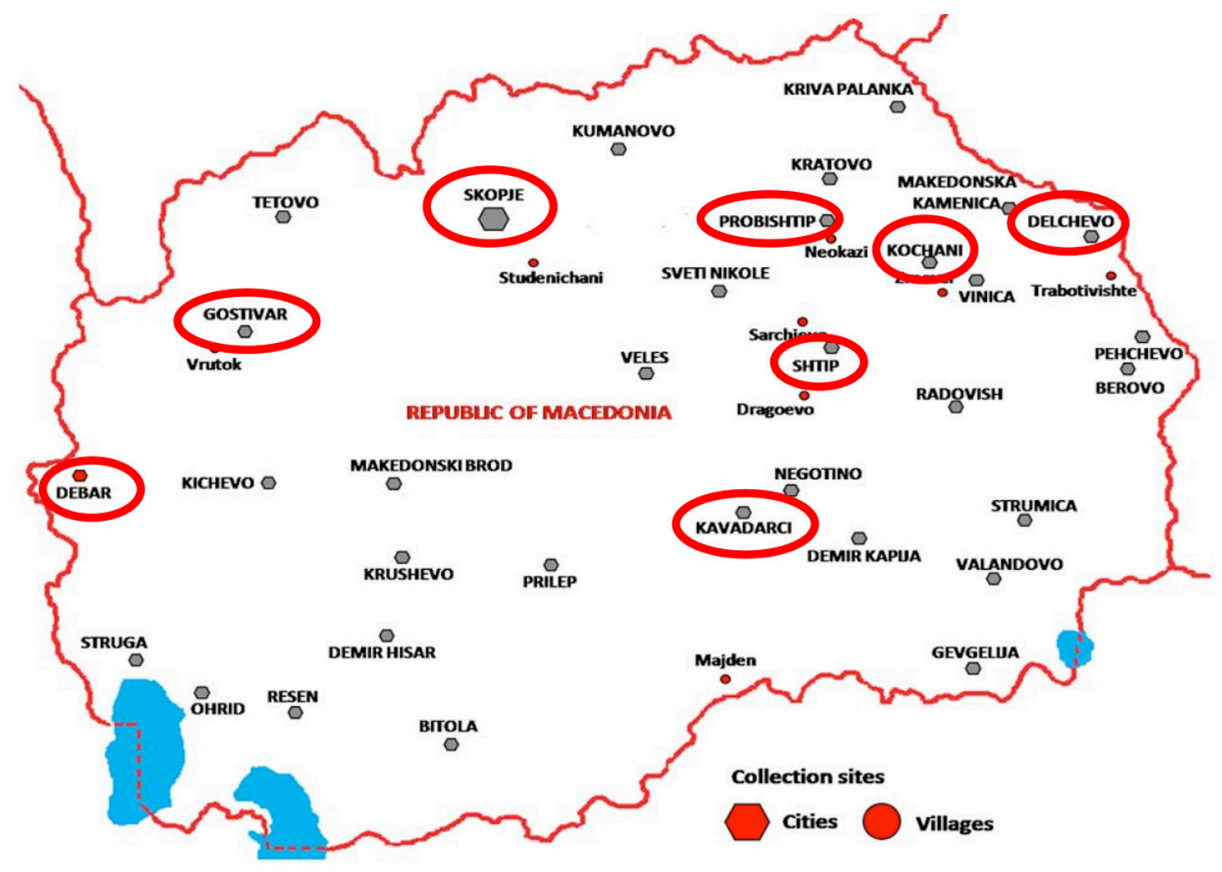

grown in 2015 at two locations: Zemun Polje (4452' 1' N N, 20¹9' 16” E, 80 m a.s.1.), Serbia, and Kumanovo (42 $05^{\circ}$ N, 21 ${ }^{\circ} 40^{\prime}$ E, 340 m a.s.1.), Republic of Macedonia, in randomized complete block design with two replicates. In Zemun Polje the soil was Mollisols and in Kumanovo the soil was Vertisol. At both locations, the usual cultivation practice for maize was applied. Plants were sown in single row plots with 15 hills per row and spaced $0.75 \mathrm{~m}$ apart with intra-row spacing of $0.4 \mathrm{~m}$ between hills. Plots were overplanted and thinned to two plants per hill after seedling establishment. Two landraces from FASFMK were with very low germination rate, and were excluded from morphological evaluation, and in total, 28 accessions were studied.

\section{Data collection and statistical analysis}

Twenty-one morphological traits were recorded for each entry using maize IBPGR descriptor (IBPGR, 2008). Plant traits were measured on 10 randomly chosen plants per plot and averaged at both locations: Plant height (PH), ear height (EH), leaf width (LW), leaf length (LL), number of leaves above the uppermost ear including ear leaf (NoL). Number of days from planting to tasseling (DT) and silking (DS) were calculated, too. Ear leaf length was measured in $\mathrm{cm}$ after pollination; also, the width of the same leaf was measured at the widest point, in $\mathrm{cm}$ (LW, Tollenar et al., 2004). Ear traits were measured on 10 ears after harvesting and drying to $14 \%$ of moisture content: Ear length (EL), number of rows per ear (NRE), number of kernels per row (NKR), ear diameter (ED), cob diameter (CD). Kernel characters were measured on 10 kernels selected from the central part of each evaluated ear: Kernel length (KL), kernel width (KW), kernel thickness (KT), 1000 kernels weight (TKW), kernel type (Ktyp), and kernel color (Kcol). Following traits were visually evaluated: Foliage rating (F), tassel type (TM), ear shape (ES), and row arrangement (RA). Leaf samples for SSR analysis were collected from 15 plants per replicate, in Zemun Polje, after flowering.

Principal components analysis (PCA) was performed on the correlation matrix of 28 landraces and 21 response variables. Components were extracted until the Eigen value $>1$. Eigen vectors were used to identify traits that best differentiated landraces. The first two PC scores, PC1 and PC2 that accounted for maximum variability of the tested parameters, were used to group the landraces. The standardized values ( mean $=0, \mathrm{sd}=1$ ) of all analyzed traits were utilized for estimating the Euclidian distance between the accessions. The obtained distance matrix was clustered with the unweighted pair-group method with arithmetic averages (UPGMA) for creation of a dendrogram. All analyses were performed using R 3.3.1 statistical software (R Foundation for Statistical Computing, Vienna, Austria). 


\section{DNA extraction and SSR analysis}

At the flowering stage, leaf tissue from each plant was collected. Isolation of DNA was done using 'population DNA bulk strategy' (Rebourg et al., 2001; 2003; Wasala and Prasanna, 2013). DNA samples from each of the 28 accessions were isolated by pooling an equal amount of leaf material from 15 individuals per population. Harvested leaves were kept frozen at $-30^{\circ} \mathrm{C}$ and powdered with liquid nitrogen. Total genomic DNA was extracted and purified from $0.1 \mathrm{~g}$ of the powder by a CTAB method (Saghai-Maroof et al., 1984). The DNA was quantified and assessed for purity spectrophotometrically, and diluted to a working concentration of $50 \mathrm{ng} \mu \mathrm{L}^{-1}$.

A total of 25 microsatellite markers were chosen from the maize database of public SSRs (http://www.maizegdb.org). Markers were selected based on amplification size and quality, and whole genome coverage. Primers were excluded from the study when banding patterns were difficult to score accurately on acrylamide gels, or when they failed to amplify consistently in all genotypes. A final set of 20 SSR primers were applied in the analysis of the genotypes according to the method of Senior et al. (1998).

The amplification reaction was carried out in $25 \mu \mathrm{L}$ reaction volume containing 1x enzyme buffer, $2.4 \mathrm{mM} \mathrm{MgCl}$, $200 \mu \mathrm{M}$ dNTP, $0.5 \mu \mathrm{M}$ primers, 1xBSA, $1 \mathrm{U}$ Taq polymerase and $50 \mathrm{ng}$ DNA template. Touch-down amplifying program was applied (thermocycler TProfessional Standard 96, Biometra GmbH, Göttingen, Germany) as follows: Initial denaturation at $95{ }^{\circ} \mathrm{C}$ for $5 \mathrm{~min}, 15$ cycles of denaturation at $95{ }^{\circ} \mathrm{C}$ for $30 \mathrm{~s}$, annealing at $63.5^{\circ} \mathrm{C}$ for $1 \mathrm{~min}$ $\left(-0.5^{\circ} \mathrm{C}\right.$ cycle $\left.{ }^{-1}\right)$ and extension at $72{ }^{\circ} \mathrm{C}$ for $1 \mathrm{~min}$, then 22 cycles of denaturation at $95^{\circ} \mathrm{C}$ for $30 \mathrm{~s}$, annealing at $56^{\circ} \mathrm{C}$ for $1 \mathrm{~min}$ and extension at $72{ }^{\circ} \mathrm{C}$ for $1 \mathrm{~min}$ and finally elongation at $72{ }^{\circ} \mathrm{C}$ for $4 \mathrm{~min}$. The amplified DNA fragments were separated using $8 \%$ polyacrylamide gel electrophoresis for $1.5 \mathrm{~h}$ at $80 \mathrm{~mA}$. After staining with ethidiumbromide for $30 \mathrm{~min}$, gels were photographed under UV light using BioDocAnalyze Live gel documentation system (Biometra, Analytik Jena AG, Jena, Germany). The alleles were scored manually and their sizes were estimated in comparison with 20 bp DNA Ladder (Thermo Scientific, Waltham, Massachusetts, USA).

The number of alleles per locus, Polymorphism Information Content (PIC) and number of unique alleles for in situ and ex situ populations and the whole set of data were estimated using the software PowerMarker 3.25 (Liu and Muse, 2005). Genetic distances were estimated using Roger's coefficient (Rogers, 1972) according to allele frequencies and the obtained distance matrix was used in cluster analysis. UPGMA method was applied to obtain the dendrogram.

\section{RESULTS}

\section{Phenotypic variability}

This study evaluated phenotypic and molecular diversity of maize landraces collected in the Republic of Macedonia, in $40 \mathrm{yr}$ period. The PCA (Figure 2) identifies five PCs with Eigen value $>1$, which explained $80 \%$ of the total phenotypic variation. In the first PC, explained 34\% of the total variability, the most important traits were PH, LL, NKR, and EL. The second PC was associated mostly with DT, DS, Ktyp and NRE, encompassing $24 \%$ of the total variance. This component was negatively correlated with cob and kernel traits. The third PC, accounted $10 \%$ of the total variation, was determined by ED and LW, while fourth and fifth PCs explained $7 \%$ and $6 \%$ of the total variation, accordingly. Biplot of PC1 vs. PC2 gave both, the information on association among traits and separation of landraces based on their morphological diversity and/or similarity. Distance of landrace from the biplot measures the difference from a hypothetical 'average' genotype that has an average level for all traits (Yan and Fregeau-Reid, 2008). Large distance of the landraces 9, 10, 13, 14 and 19 indicate that they have extreme values for one or more traits. Besides, relation among traits could be indicated by the angle between trait vectors (Yan and Kang, 2003). The strongest positive association, indicated by acute angles, was determined between DT and DS, and between PH, LL and EL. The landraces showed the greatest variability for plant height and ear length, and the lowest difference for flowering dates.

Dendrogram for morphological traits grouped landraces in two sub-clusters (Figure 3), predominantly based on collecting time. There was one outlier (ZP 1645-landraces 22), solely separated and the most distanced from the others, due to the shortest PH, LL, and EL, and the smallest number of days from planting to flowering, that did not belong to any cluster. Smaller cluster consists of landraces 9, 10,13, 14 and 19, separated from the others due to 
Figure 2. Biplot of morphological traits of the maize landraces. Analysis explained $57.5 \%$ of observed field variability. The most discriminative traits are rounded in red color.

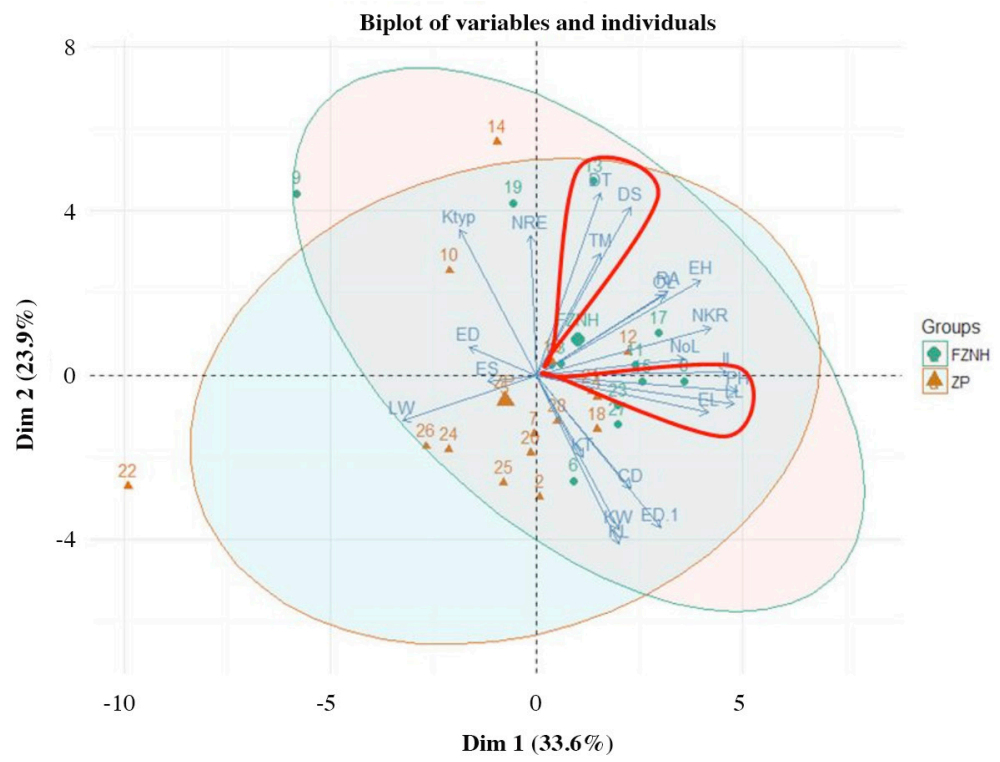

extreme value of traits, like it was previously shown on bi-plot (Figure 2). These sub-clusters consisted of pairs of accessions from different gene banks, as being with pop-corn kernel type. Within second cluster, recently collected landraces from MKGB have greater plant height, and number of days from planting to flowering, whereas accessions from the MRIZP gene bank, have shorter plants $(<2 \mathrm{~m})$ and number of days from planting to flowering less than $75 \mathrm{~d}$. Pairs of samples from the same gene bank formed small sub-clusters according to collecting time and site.

Figure 3. Classification of maize landraces as revealed by UPGMA cluster analysis based on morphological traits.

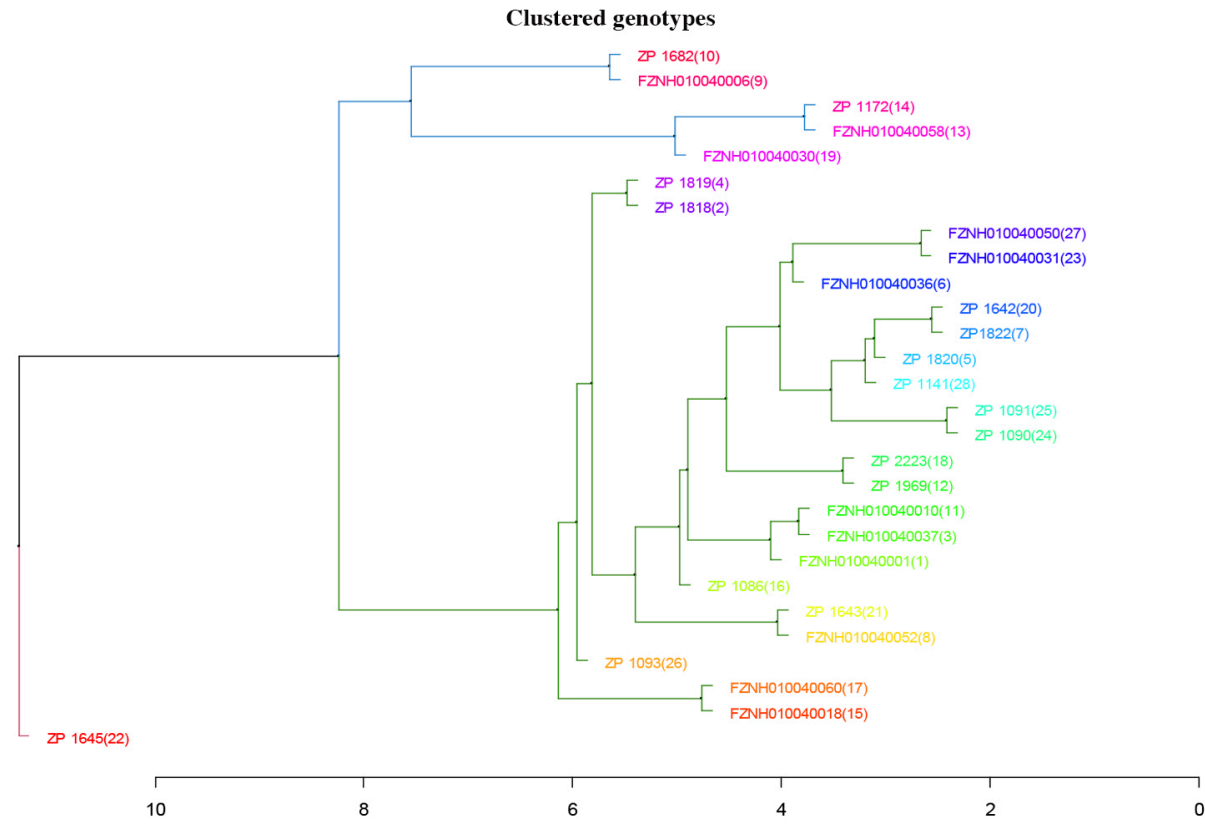




\section{SSR based variability}

With 20 SSR loci distributed uniformly over all 10 maize chromosomes, in total 173 alleles with an average of 6.18 alleles per locus were detected among 28 landraces. The number of alleles per primer was in a range from two to 13. PIC values were in range from 0.32 to 0.80 , with average value of 0.67 . In total, 16 unique alleles were detected, four in in situ and 12 in ex situ populations. The genetic analysis of maize accessions based on SSR polymorphism classified landraces into the three gene pools (Figure 4).

The accessions were grouped according to collecting sites: In the first sub-cluster were four accessions collected in the vicinity of town Stip. The second sub-cluster consists of two samples, from both gene banks. Although they were collected from different sites (Kocani and Debar), and differ in kernel type, they share high similarity at molecular level (0.781). The third group consists of 13 previously collected landraces (MRIZP gene bank), and seven landraces from FASFMK collection. They could be grouped in small cluster of eight samples collected in the vicinity of Stip. Another two sub-clusters had nine samples collected in the Western Macedonia region (Gostivar and Debar), and three from the Eastern part (Delcevo, Probistip and Kicevo).

The only samples grouped together for both, morphological and SSR markers, were ZP 1172 and FZNH 06 (landraces 13 and 14), with coefficient of similarity of 0.844 .

Figure 4. Classification of maize landraces based on SSR marker analysis.

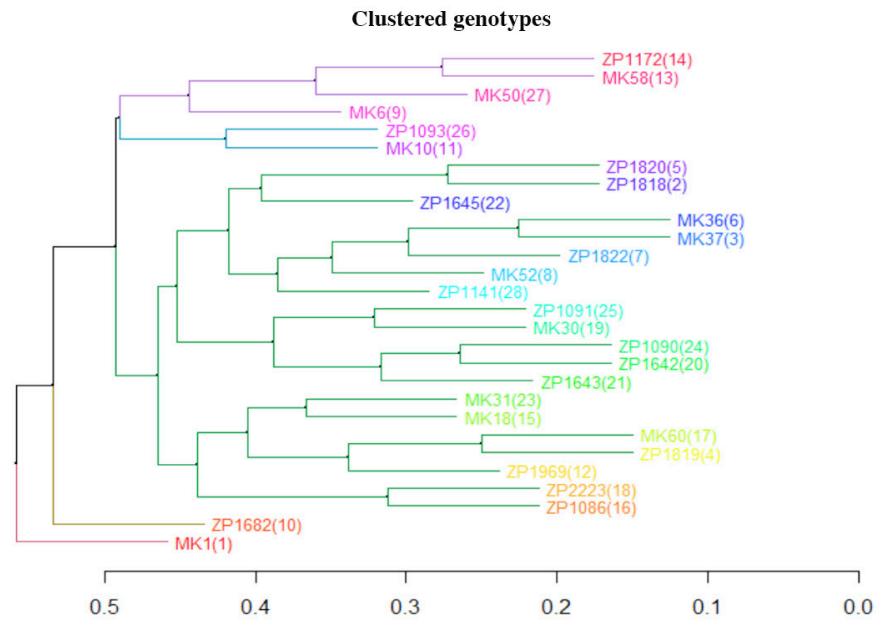

\section{DISCUSSION}

The phenotypic characterization of plant genetic resources is necessary for optimal exploitation by breeders. However, the usefulness of morphological characterization is rather limited, because of the significant environmental impact on expression of characters. Application of DNA markers, unaffected by environment, successfully discriminate closely related genotypes and possible duplicate accessions in many crops (Börner et al., 2000; Lund et al., 2003). Morphological and genetic variations are important to estimate variability, potential loss of diversity and the best accessions for conservation and possible utilization in breeding (Beyene et al., 2005).

Redundant duplication increased costs for storage and multiplication, without widening of genetic diversity. Efficient gene bank management comprehended increased number of samples and reduction of financial resources for their maintenance, by identification and removal of redundant germplasm (Hintum et al., 1996). Different authors distinguish the term 'duplicate accession' between historical, genetic or biological duplicates. Historical duplicates could be treated as genetic duplicates, if passport data together with genetic composition of the accessions have high similarity (Hintum et al., 1996; Willner et al., 1998; van Treuren et al., 2001). However, handling, multiplications and maintenance within gene bank, could lead to diversifications of accession from their original samples, and they are very seldom completely genetically identical. The level of genetic diversity between potential duplicates is 
not clearly defined, particularly for allogamous species (Lund et al., 2003). Identification of absolutely genetically identical samples is possible by comparison of complete genome, which is very expensive and not necessary for samples considered as duplicates in gene bank (van Treuren et al., 2001). In practice, samples from the same outcrossing population will not be completely identical, but will have a similar genetic origin.

In the present study, morphological characterization for 41 descriptors (IBPGR, 2008) was performed. The effect of flowering influenced grouping of landraces, i.e. number of days from planting to silking and tasseling, as being the most stable traits, with the lowest variation. It was obvious that newly collected samples were with greater number of days from planting to flowering, compared to previously collected accessions conserved in MRIZP gene bank. Apparently, in seed multiplication process, either in gene banks or on farmers' fields, pollination (natural or artificial) occurs among plants flowering simultaneously. Important role of earliness/flowering time on morphological variation and differentiation was reviled in the analysis of traditional European maize populations (Rebourg et al., 2001) and in the studies of local maize landraces in Turkey (Cömertpay et al., 2012).

The cluster analysis based on morphological traits was appropriate considering length of vegetation season, plant height, and leaf length. However, landraces were not distinguished according to the collecting site, rather based on collecting time. Apparently, during nearly $50 \mathrm{yr}$ (between first and last collecting missions) migration and seed exchange between farmers, contributed to adaptation to different agro-climatic conditions, which further influenced the changes in phenotypic characteristics of landraces. Previously collecting, ex-situ accessions were characterized by higher plants, longer leaves and greater number of kernels per row. Limitation of morphological data for discrimination of landraces according to geographical origin was revealed in different studies on heterogeneous maize landraces (Sharma et al., 2010; Cömertpay et al., 2012). Nevertheless, morphological variation in maize was of high importance during evaluation in different environments, when expression of particular trait could be valuable for utilization in breeding.

For efficient genetic resources conservation, it is important to know whether phenotypically similar genotypes share similarity in gene combinations. Microsatellite markers are appropriate for the assessment of genetic diversity given their informativeness, co-dominance, high polymorphism, repeatability, and simplicity (Reif et al., 2005; Bourguiba et al., 2010). In numerous diversity studies, application of SSRs was appropriate for grouping accessions according to their geographical origin, e.g. in bean (Sharma et al., 2013), tomato, (Mercati et al., 2015), maize (Cömertpay et al., 2012). Based on SSR markers, maize landraces from the same small area were in the group with genetically similar accessions (Figure 4). The average number of alleles per locus is a measure of genotypic diversity. In our study it was 6.18, very similar to reported numerous studies on maize landraces diversity (Qi-Lun et al., 2008; Cömertpay et al., 2012). This value indicates a great level of diversity, since the set of used SSR primers was based on specificity and informativeness.

Usually, reports about great phenotypic variability of traditional landraces indicated minor genetic differences between or within populations grown in the same region. In the present study, examined landraces showed considerable degree of variation in morphological traits. Genetic difference of landraces from ex situ and in situ conservation was due to regeneration and/or conservation in $40 \mathrm{yr}$ period. Only two samples (landraces 13 and 14, as in situ and ex situ conserved accessions, respectively) expressed the highest similarity coefficient, clustered together for both morphological and molecular markers, and shared very similar genetic background (0.844). Thus, the in situ accession could be considered as duplicate sample and will not be introduced to MRIZP collection, since redundant germplasm decrease the efficiency of every genetic resource management.

There is evidence that ex situ conservation preserve alleles that have been lost in populations under in situ conservation. Ex situ samples of American Indian Hopi maize landraces, compared by morphological and SSR markers, differed significantly from their in situ accessions (Soleri and Smith, 1995). Similar level of genetic diversity of ex situ and in situ samples of Jala maize could be addressed to good maintenance practice in gene bank (Rice et al., 2006).

The main factor affecting diversity is selection by farmers. Numerous studies reported various factors, such as biological, socio, and economical that influenced farmers to choose and maintain, or eliminate particular landraces for further use (Jarvis et al., 2000). During planting, growing and harvesting, farmers also made a kind of selection that might cause the narrowing of genetic variability. Advances in agricultural practice and decrease of rural 
development over 40 yr resulted in more careful farmers' attention towards varieties selection and seed production. On the other side, multiplication and regeneration of accessions in gene banks are aimed to keep genetic variability and diversity of original sample. Assessment of the accessions within gene bank and identification of variation on morphological and molecular level are also, very valuable for development of core collections and utilization in breeding, as well as for rationalization and elimination of redundant germplasm.

\section{CONCLUSIONS}

Efficient collection, conservation and utilization of plant genetic resources include periodical comparison of ex situ and in situ samples. Application of morphological and molecular markers (e.g. appropriate set of SSR markers) could be efficient for identification of possible duplicates. In the present study, greater total number of alleles and unique alleles were found in ex situ than in situ populations, indicating that farmer activities reduced allelic richness in recently collected landraces. Compared to ex situ gene bank accessions, newly collected landraces lost some alleles, and changed some traits, due to local cultivation practice, climatic and geographical conditions, and artificial selection by farmers. Obtained results are in line with general consensus that the most effective strategy for crop germplasm conservation is integration of both, in situ and ex situ concept. Through adequate management, ex situ MRIZP gene bank collection successfully preserve genetic diversity for future needs. In addition, landraces that clustered together either by morphological or molecular markers, could be used for development of core collections for breeding purposes.

\section{ACKNOWLEDGEMENT}

This work was supported by Ministry of Education, Science and Technological Development, Republic of Serbia, through the project TR31068-Improvement of maize and soybean traits by molecular and conventional breeding.

\section{REFERENCES}

Andjelkovic, V., and Ignjatovic-Micic, D. 2012. Maize genetic resources-science and benefits. Serbian Genetic Society and Maize Research Institute Zemun Polje, Belgrade, Serbia.

Barcaccia, G., Volpato, M., Gentili, R., Abeli, T., Galla, G., Orsenigo, S., et al. 2016. Genetic identity of common buckwheat (Fagopyrum esculentum Moench) landraces locally cultivated in the Alps. Genetic Resources and Crop Evolution 63:639-651.

Beyene, Y., Botha, A., and Myburg, A. 2005. A comparative study of molecular and morphological methods of describing genetic relationships in traditional Ethiopian highland maize. African Journal of Biotechnology 4(7):586-595.

Börner, A., Chebotar, S., and Korzun, V. 2000. Molecular characterisation of the genetic integrity of wheat (Triticum aestivum L.) germplasm after long-term maintenance. Theoretical and Applied Genetics 100:494-497.

Bourguiba, H., Krichen, L., Audergon, J.M., Khadari, B., and Trifi-Farah, N. 2010. Impact of mapped SSR markers on the genetic diversity of apricot (Prunus armeniaca L.) in Tunisia. Plant Molecular Biology Reporter 28:578-587.

Cömertpay, G., Baloch, F.S., Kilian, B., Ülger, A.C., and Özkan, H. 2012. Diversity assessment of Turkish maize landraces based on fluorescent labelled SSR markers. Plant Molecular Biology Reporter 30:261-274.

Drinic Mladenovic, S., Andjelkovic, V., and Ignjatovic Micic, D. 2012. Genetic diversity of maize landraces as sources of favorable traits. p. 89-112. In Caliskann, M. (ed.) The molecular basis of plant genetic diversity. InTech, Rijeka, Croatia.

FAO. 1996. The state of the world's plant genetic resources for food and agriculture. FAO, Rome, Italy.

Hintum, Th.J.L. van, Boukema, I.W., and Visser, D.L. 1996. Reduction of duplication in a Brassica oleracea germplasm collection. Genetic Resources and Crop Evolution 43:343-349.

IBPGR. 2008. Descriptor for maize. International Board for Plant Genetic Resources (IBPGR), Rome, Italy.

Ignjatovic-Micic, D., Mladenovic Drinic, S., Nikolic, A., and Lazic-Jancic, V. 2008. SSR analysis for genetic structure and diversity determination of maize local populations from former Yugoslavia territories. Russian Journal of Genetics 44(11):1317-1324.

Jarvis, D.I., Meyer, L., Klemick, H., Guarino, L., Smale, M., Brown, A.H.D., et al. 2000. Training guide for in situ conservation on-farm. Version 1. 161 p. International Plant Genetic Resources Institute, Rome, Italy.

Liu, K., and Muse, S.V. 2005. PowerMarker: an integrated analysis of environment for genetic marker analysis. Bioinformatics 21:2128-2129. 
Lund, B., Ortiz, R., Skogaard, I.M., and Waugh, R. 2003. Analysis of potential duplicates in barley gene bank collections using re-sampling of microsatellite data. Theoretical and Applied Genetics 106:1129-1138.

Mercati, F., Longo, C., Poma, D., Araniti, F., Lupini, A., Mammano, M.M., et al. 2015. Genetic variation of an Italian long shelf-life tomato (Solanum lycopersicum L.) collection by using SSR and morphological fruit traits. Genetic Resources and Crop Evolution 62:721-732.

Qi-Lun, Y. Ping, F., and Shu-Xian, Z. 2008. Constructing a core collection for maize (Zea mays L.) landraces from Wuling mountain region in China. Agricultural Science China 7(12):1423-1432.

Rebourg, C., Chastanet, M., Gouesnard, B., Welcker, C., Dubreuil, P., and Charcosset, A. 2003. Maize introduction into Europe: the history reviewed in the light of molecular data. Theoretical and Applied Genetics 106:895-903.

Rebourg, C., Gouesnard, B., and Charcosset, A. 2001. Large scale molecular analysis of traditional European maize populations. Relationships with morphological variation. Heredity 86:574-587.

Reif, J.C., Hamrit, S., Heckenberger, M., Scipprack, W., Maurer, H.P., Bohn, M., et al. 2005. Trends in genetic diversity among European maize cultivars and their parental components during the past 50 years. Theoretical and Applied Genetics 111:838-845.

Reif, J.C., Xia, X.C., Melchinger, A.E., Warburton, M.L., Hoisington, D.A., Beck, D., et al. 2004. Genetic diversity determined within and among CIMMYT maize populations of tropical, subtropical, and temperate germplasm by SSR markers. Crop Science 44:326-334.

Rice, E.B., Smith, M.E., Mitchell, S.E., and Kresovich, S. 2006. Conservation and change: a comparison of in situ and $e x$ situ conservation of Jala maize germplasm. Crop Science 46:428-436.

Rogers, J.S. 1972. Measures of genetic similarity and genetic distances. Studies in Genetics VII. University of Texas Publication 7213. p. 145-153. University of Texas, Austin, Texas, USA.

Saghai-Maroof, M.A., Soliman, K.M., Jorgensen, R.A., and Allard, R.W. 1984. Ribosomal DNA spacer-length polymorphism in barley: Mendelian inheritance, chromosomal location, and population dynamics. Proceedings of National Academy of Science of United States of America 81:8014-8018.

Senior, M.L., Murphy, J.P., Goodman, M.M., and Stuber, C.W. 1998. Utility of SSRs for determining genetic similarities and relationships in maize using an agarose gel system. Crop Science 38:1088-1098.

Sharma, P.N., Díaz, L.M., and Blair, M.W. 2013. Genetic diversity of two Indian common bean germplasm collections based on morphological and microsatellite markers. Plant Genetic Resources 11(2):121-130.

Sharma, L., Prasanna, B.M., and Ramesh, B. 2010. Analysis of phenotypic and microsatellite-based diversity of maize landraces in India, especially from the north east Himalayan region. Genetica 138(6):619-31.

Soleri, D., and Smith, S.E. 1995. Morphological and phenological comparison of two Hopi maize varieties conserved in situ and ex situ. Economic Botany 49:56-77.

Tollenar, M., Ahmadzadeh, A., and Lee, E.A. 2004. Physiological basis of heterosis for grain yield in maize. Crop Science 44:2086-2094.

van Treuren, R., van Soest, L., and van Hintum, T. 2001. Marker-assisted rationalisation of genetic resource collections: A case study in flax using AFLPs. Theoretical and Applied Genetics 103:144-152. https://doi.org/10.1007/s001220100537.

Yan, W., and Fregeau-Reid, J. 2008. Breeding line selection based on multiple traits. Crop Science 48:417-423.

Yan, W., and Kang, M.S. 2003. GGE biplot analysis: A graphical tool for breeders, geneticists and agronomists. CRC Press, Boca Raton, Florida, USA.

Wasala, S., and Prasanna, B.M. 2013. Microsatellite marker-based diversity and population genetic analysis of selected lowland and mid-altitude maize landrace accessions of India. Journal of Plant Biochemistry and Biotechnology 22:392-400.

Willner, E., Sackville Hamilton, N.R., and Knupffer, H. 1998. Duplications in forages collections. p. 92-95. In Maggioni, L., Marum, P., Sackville Hamilton, R., Thomas, I., Gass, T., and Lipman, E. (eds.) Report of a Working Group on Forages, $6^{\text {th }}$ Meeting, Beitostolen, Norway. 6-8 March 1997. International Plant Genetic Resources Institute (IPGRI), Rome, Italy. 